\title{
Implicações no Capital Próprio da Atual Contabilização dos Subsídios Relacionados com Ativos. Evidência de uma Amostra de Empresas do Setor Agrícola Português
}

\author{
Implications on Financial Autonomy Resulting from the Current \\ Accounting System on Grants Related to Assets: Evidence from a Sample \\ of Portuguese Agricultural Businesses
}

\author{
José Manuel Teixeira $^{1}$; Amélia Ferreira-da-Silva ${ }^{2}$; Maria José Dos-Santos ${ }^{3}$
}

${ }^{1}$ E-mail: jpereira@ipca.pt; Polytechnic Institute of Cávado and Ave, Accounting Department, CICF

2 Institute of Accounting and Administration of Porto; Centro de Estudos em Economia, População e Sociedade - CEPESE, CECEJ

E-mail: mjpls1963@gmail.com; Polytechnic Institute of Lisboa

\section{Resumo}

O novo Sistema de Normalização Contabilístico, em vigor a partir de 2010, veio revogar todo o normativo contabilístico português. Em comparação com o normativo anterior, este novo normativo veio preconizar procedimentos contabilísticos diferentes relativamente à contabilização dos subsídios relacionados com ativos. O objetivo deste estudo é analisar o impacto no capital próprio da contabilização dos subsídios preconizado no novo normativo, numa amostra de empresas do setor agrícola. Para alcançar o objetivo proposto procedemos a recolha da informação financeira referente ao exercício de 2009 de uma amostra de 124 empresas do setor agrícola, extraída da base de dados SABI, e que receberam subsídios para investimento nesse ano. Com base nos dados analisados podemos deduzir que o valor do capital próprio das empresas em estudo registará uma variação positiva, correspondente ao valor ainda não imputado dos subsídios reconhecidos, que corresponde a um aumento de quase $4,5 \%$. Esse incremento faz com que o indicador de autonomia financeira aumente, em média, 4,7\%, sendo o impacto também positivo no rácio de solvabilidade, com uma variação média superior a $11 \%$. O fato do novo Sistema de Normalização Contabilística preconizar um tratamento contabilístico diferente do estabelecido na IAS 20, permite às empresas portuguesas apresentarem indicadores econômicos financeiros próximos dos apresentados por empresas congêneres de outros países europeus, onde o reconhecimento inicial do subsídio em capital próprio é o que vigora. Além disso, quando a apresentação de candidaturas a fontes de financiamento ou a determinados programas ou fundos europeus poderão aumentar as suas hipóteses de sucesso, pois estes exigem na maioria das vezes que as empresas apresentem percentagens ou valores mínimos em determinados rácios.

Palavras-chave: Subsídios; Capital Próprio; Autonomia Financeira; Solvabilidade; Empresas Agrícolas.

\footnotetext{
Abstract

The new System of Accounting Standards, effective since 2010, repealed all the Portuguese accounting standards. Compared to the former standards, the new normative advocates for different accounting procedures regarding the recognition of grants related to assets. The objective of this study is to analyze the impact on financial autonomy for grants recommended under the new standard in a sample of companies from the agricultural sector. To achieve the proposed objective, we proceeded to collect financial information from the year 2009 from a sample of 124 companies in the agricultural sector that were randomly selected from the SABI database from a list of those that had received subsidies for investment in that year. Based on the data analyzed, we can
} 
deduce that the value of the equity of the companies in the study will register a positive variation, corresponding to the not yet recorded value of recognized subsidies, which corresponds to an increase of nearly $4.5 \%$. This increase causes the indicator of financial autonomy to increase, on average, by $4.7 \%$, and also has a positive impact on the solvency ratio, with an average variation greater than $11 \%$. The fact that the new System of Accounting Standards advocates for accounting procedures that are different from those set out in the IAS 20 allows Portuguese companies to present economic financial indicators similar to those being presented by like companies in other European countries, where the initial recognition of the grant in equity is what counts. Also, this may also increase the chance of success for applications to funding sources or determined European programs or funds, as such funding sources normally require that companies show percentages or minimum values in certain ratios.

Keywords: Grants. Equity; Financial autonomy; Solvency; Agricultural Companies.

\section{Introdução}

Assistimos nas últimas décadas a um desenvolvimento significativo da economia mundial. A deslocalização de muitas empresas tornou-se um fenômeno corrente, acarretando muitos aspetos negativos, apesar de ter beneficiado muitas organizações multinacionais. O desenvolvimento dos mercados financeiros permitiu uma grande mobilidade dos seus capitais, significativa liquidez e facilidade de acesso aos diversos investidores.

Uma vez que a informação financeira era preparada para os diferentes utilizadores de acordo com um conjunto de princípios e procedimentos que diferiam de país para país, naturalmente que a comparabilidade das diversas DF's era tarefa muito difícil, tornava mais complexa a consolidação de contas, conduzia a maiores custos das tarefas contabilísticas e dificultavam os mecanismos de controlo. Tudo isto concorreu para facilitar a aceitação das Normas Internacionais de Contabilidade (IAS). O processo de convergência das práticas contabilísticas a nível internacional tornou-se uma realidade e tem sido impulsionado por diversos organismos internacionais, tais como o International Accounting Standards Board (IASB), o International Organization of Securities Commissions (IOSCO), a União Europeia (UE) e o Securities and Exchange Commission (SEC). Para Ding, Jeanjean, \& Stolowy (2005), o processo de harmonização contabilística tem como objetivos transmitir informação de qualidade aos seus utilizadores, de forma a garantir a eficiência dos mercados, reduzirem o custo de produção de informação e transmitir uma imagem única e fiável para o mercado.

Em Portugal, o primeiro passo para a harmonização contabilística foi dado com a publicação do Decretolei 47/77, que aprovou o primeiro Plano Oficial de Contabilidade, muito influenciado pela normalização contabilística francesa, e culminou com a implementação do Sistema de Normalização Contabilística, aprovado pelo Decreto-Lei $n^{\circ}$ 158/2009, para entrar em vigor em janeiro de 2010. Conforme se pode ler no seu preâmbulo o SNC resulta da adaptação, das NIC do IASB, indicando que a normalização contabilística nacional deverá aproximar-se, tanto quanto possível, dos novos padrões comunitários, por forma a proporcionar ao nosso país o alinhamento com as diretivas e regulamentos em matéria contabilística da UE, sem ignorar, porém, as características e necessidades específicas do tecido empresarial português. O atual modelo contabilístico apresenta um conjunto de novos 
procedimentos, alterando consequentemente a informação contida nas DF's, e está assente em princípios, e não em regras tal como acontecia no POC.

\section{Breve Revisão da Literatura}

Após a publicação do Regulamento 1606/2002, que obrigava as empresas cotadas dos Países Membros a utilizar as IFRS foram vários os autores tentaram perceber quais as alterações ocorridas com a transição para o novo modelo contabilístico. Dos vários trabalhos, faremos de seguida uma breve referência aos que foram mais citados na literatura sobre o tema. Hung e Subramanyam (2007) estudaram as implicações da adoção das IAS na Alemanha, em substituição do Germany Accounting Rules, através da análise das Demonstrações Financeiras e dos principais Rácios, tendo concluído que os Ativos Totais e o valor contabilístico do Capital Próprio, bem como as variações no book-value e nos resultados, são significativamente superiores sob IAS/IFRS do que sob normas alemãs.

Em Espanha, Perramon e Amat (2007) realizaram um estudo, onde efetuaram a primeira análise da implementação das IAS/IFRS, nas Demonstrações Financeiras de empresas Espanholas, cotadas e não cotadas. A comparação entre as normas Espanholas e as IAS/IFRS levou a concluir que ocorreram alterações significativas nos Resultados Líquidos.

Com base num grupo de empresas do Reino Unido, Stenka, Ormrod, e Chan (2008) procuraram estudar o impacto das IAS/IFRS nesse território, tentando identificar quais as alterações ocorridas na rentabilidade da empresa, no seu patrimônio, bem como indagar as razões para estas alterações. Os autores concluíram que o Resultado Líquido sofreu alterações significativas, sendo estas provocadas pelas modificações contabilísticas introduzidas ao nível do goodwill.

Armstrong, Barth, Jagolinzer, e Riedl (2010) realizaram um estudo onde observaram a reação do mercado europeu de ações, a um conjunto de dezasseis eventos relacionados com a adoção das IFRS. Observaram resultados genericamente positivos, para empresas sedeadas em países de corrente continental.

Bianchi (2009) desenvolveu um estudo em que procurou analisar os efeitos da adoção das IAS/IFRS nas Demonstrações Financeiras das empresas portuguesas não cotadas, tentando identificar, cumulativamente, se os efeitos das adoções das IAS/IFRS, são coincidentes com determinados estudos já realizados, bem como quais as motivações que lhes assistiam, para levar as empresas a iniciar o processo de mudança para o novo normativo.

Na literatura também é possível encontrar trabalhos sobre os efeitos da adoção das IAS/IFRS, nas Demonstrações Financeiras das empresas portuguesas não cotadas, de que são exemplo os elaborados por Pires e Rodrigues (2010) e Costa e Teixeira (2013). Neste trabalho, não seguiremos a metodologia dos referidos anteriormente. Como objetivo deste estudo propomo-nos analisar o impacto no capital próprio da contabilização dos subsídios preconizado no novo normativo, numa amostra de empresas do setor agrícola, não sendo objeto de estudo a implicação global da transição para o novo normativo. 


\section{A Contabilização dos Subsídios do Governo e Divulgação de Apoios do Governo}

A IAS 20 estabelece o tratamento contabilístico e divulgação de subsídios do Governo e estipula os requisitos de divulgação dos apoios do Governo. Esta norma promulgada em novembro de 1982 mantevese inalterada durante vários anos.

No atual normativo contabilístico português a NCRF22 teve por base a correspondente IAS 20 adotada pela UE. Embora idênticas quanto aos requisitos para o reconhecimento de um subsídio do Governo, divergem na forma de tratamento contabilístico dos subsídios relacionados com a aquisição de ativos.

Para a IAS20, por regra, os subsídios do Governo devem ser reconhecidos como rendimentos, numa base sistemática, durante os períodos necessários para balanceá-los com os custos relacionados, que se pretende que eles compensem, em conformidade com o seu $\$ 24$, em que prescreve que os subsídios do Governo relacionados com ativos, incluindo os subsídios não monetários pelo justo valor, devem ser apresentados no balanço quer tomando o subsídio como rendimento diferido quer deduzindo o subsídio para chegar à quantia escriturada do ativo.

De acordo com o parágrafo 12 da NCRF 22 os subsídios do Governo não reembolsáveis relacionados com ativos fixos tangíveis e intangíveis devem ser inicialmente reconhecidos nos Capitais Próprios. Subsequentemente devem ser imputados numa base sistemática como rendimentos durante os períodos necessários para balanceá-los com os gastos relacionados que se pretende que eles compensem, no caso de serem respeitam a ativos fixos tangíveis depreciáveis e intangíveis com via útil definida. Se respeitarem a ativos fixos tangíveis não depreciáveis e intangíveis com vida útil indefinida, devem ser mantidos nos Capitais Próprios, exceto se a respetiva quantia for necessária para compensar qualquer perda por imparidade.

O reconhecimento inicial do subsídio em capital próprio proporciona, no ano do reconhecimento do subsídio, um incremento no capital próprio pelo valor total do subsídio. Como refere Grenha, Cravo, Baptista, e Pontes (2009), o tratamento contabilístico adaptado na versão final da NCRF22, para os subsídios relacionados com ativos, vai permitir que as entidades nacionais evidenciem indicadores financeiros efetivamente equivalentes aos que são apresentados por entidades de outros países, onde o tratamento contabilístico de tais subsídios não segue a atual IAS 20.

\section{Metodologia}

Para alcançar o objetivo proposto procedemos a recolha da informação financeira referente ao exercício de 2009 de uma amostra de 150 empresas do setor agrícola, da região Norte de Portugal, extraída da base de dados SABI, e que tinham contabilizado subsídios para investimento nesse ano. Dessa amostra eliminamos 26 empresas, pois apenas 124 apresentavam dados completos.

Com base nas suas demonstrações financeiras procedemos a recolha o valor do Capital Próprio, Ativo e Passivo. Tendo em conta que no anterior normativo os subsídios eram inicialmente reconhecidos como passivo, o montante ainda não imputado está relevado na conta Subsídios para Investimentos, que é uma conta de diferimentos. 
Assim, na transição para o novo normativo o capital próprio das empresas em análises sofrerá um incremento, correspondente ao valor ainda não imputado dos subsídios reconhecidos. Essa variação pode ter implicações nos rácios de autonomia financeira e de solvabilidade.

A autonomia financeira mede-se através do quociente entre o valor dos seus capitais próprios e o valor do seu ativo líquido num dado momento. Este conceito representa a maior ou menor capacidade de uma empresa ou entidade fazer face aos seus compromissos financeiros através dos seus capitais próprios.

O Rácio de Solvabilidade trata-se de uma medida da relação entre os capitais próprios e os capitais alheios de uma empresa. Quanto mais elevado for este rácio, mais estável financeiramente será a empresa. Pelo contrário, um valor muito baixo indicia pouca viabilidade da empresa no futuro, porque é sinônimo de uma grande fragilidade económico-financeiro.

\section{Apresentação dos resultados}

Dos resultados obtidos verificamos que o capital próprio das empresas em análise, sofreu, em média, uma variação positiva de aproximadamente 4,5\%. Tal alteração no capital próprio, considerando o valor do ativo, que se manteve inalterado, provocou uma variação positiva no rácio de autonomia financeira que, em média, aumentou 4,7\%. Esta variação média verificada neste indicador variou entre um mínimo de 0 eu m máximo de 16\%. Observamos que o rácio de autonomia financeira de 38 empresas em estudo (cerca de 30\%) não sofreu qualquer variação, o que se deve, essencialmente, a um reduzido valor de subsídios recebidos, face a um valor relativamente elevado do capital próprio.

No que respeita ao rácio de solvabilidade, a variação média de 4,5\% no capital próprio, considerando a variação simétrica provocada no passivo, implicou um aumento médio no referido rácio superior a $11 \%$.

Constatou-se que 5 empresas (4\%) não sofreram qualquer variação no seu rácio de solvabilidade e cerca de $22 \%$ das empresas do estudo, sofreu uma variação positiva superiora $15 \%$.

\section{Conclusões}

A análise efetuada teve por base apenas a implicação da contabilização dos subsídios para investimento de forma isolada, não tendo sido objeto de estudo a implicação global da transição para o novo normativo.

O fato do novo Sistema de Normalização Contabilística preconizar um tratamento contabilístico diferente do estabelecido na IAS 20, permite às empresas portuguesas apresentar indicadores económicofinanceiros próximos dos apresentados por empresas congéneres de outros países europeus onde o reconhecimento inicial do subsídio em capital próprio é o que vigora. Para além disso, aquando da apresentação de candidaturas a fontes de financiamento ou a determinados programas ou fundos europeus poderão aumentar as suas hipóteses de sucesso, pois estes exigem na maioria das vezes que as empresas apresentem percentagens ou valores mínimos em determinados rácios.

As variações verificadas no capital próprio devem ser analisadas com alguma ponderação, pois resultaram de um novo procedimento contabilístico, não se tendo registrado um real reforço ou diminuição da estrutura de capitais das empresas objeto de estudo. 


\section{Referências}

Armstrong, C. S., Barth, M. E., Jagolinzer, A. D., \& Riedl, E. J. (2010). Market Reaction to the Adoption of IFRS in Europe. The Accounting Review, 85(1), 31-61. doi:10.2308/accr.2010.85.1.31

Bianchi, M. (2009). Processo preparatório de transição POC para NCRF/SNC: motivações e impactes (Dissertação de Mestrado em Contabilidade). Faculdade de Economia da Universidade do Porto, Porto, Portugal.

Costa, P., \& Teixeira, A. (2013). O impacto da adoção do SNC no capital próprio das empresas Portuguesas.

Obtido

de http://comum.rcaap.pt/bitstream/123456789/5418/1/Artigo_comCapa.pdf

Ding, Y., Jeanjean, T., \& Stolowy, H. (2005). Why do national GAAP differ from IAS? The role of culture. The International Journal of Accounting, 40(4), 325-350. doi:10.1016/j.intacc.2005.09.004

Grenha, C., Cravo, D., Baptista, L., \& Pontes, S. (2009). Anotações ao sistema de normalização contabilística. Lisboa: Câmara dos Técnicos Oficiais de Contas.

Hung, M., \& Subramanyam, K. R. (2007). Financial statement effects of adopting international accounting standards: the case of Germany. Review of Accounting Studies, 12(4), 623-657. doi:10.1007/s11142-007-9049-9

Perramon, J., \& Amat, O. (2007). IFRS introduction and its effect on listed companies in Spain. Economics Working Papers, Obtido de http://papers.ssrn.com/sol3/papers.cfm?abstract_id=1002516

Pires, A., \& Rodrigues, F. (2010). O efeito da aplicação do SNC no Capital Próprio: Evidência em 50 empresas sujeitas a Revisão Legal de Contas. Em Livro de Actas das XXII ${ }^{a s}$ Jornadas LusoEspanholas de Gestão Científica. Sociedade, Territórios e Organizações: Inclusões e competitividade. Vila Real.

Stenka, I., Ormrod, P., \& Chan, A. (2008). Accounting for Business Combinations-The consequences of IFRS adoption for UK Listed Companies. Working Paper Keele University and University of Liverpool. 